\title{
Correlation and comparison of the infinite dilution activity coefficients in aqueous and organic mixtures from a modified excess Gibbs energy model
}

\author{
Jaw-Shin Cheng, Muoi Tang ${ }^{1}$, Yan-Ping Chen* \\ Department of Chemical Engineering, National Taiwan University, Taipei, Taiwan, ROC
}

Received 31 July 2002; accepted 11 June 2003

\begin{abstract}
Activity coefficients at infinite dilution $\left(\ln \gamma^{\infty}\right)$ of aqueous systems were calculated using a modified excess Gibbs energy model. More than 95 binary systems with 15 solute families from nonpolar alkanes to polar alcohols and acids were employed in this study. Based on the local composition lattice model developed by Aranovich and Donohue, a modified excess Gibbs energy equation (m-AD model) was derived in this study. With two generalized parameters for each homologous series of solutes, this modified model yields satisfactory results for the limiting activity coefficients. The overall absolute average deviation (AAD) of $\ln \gamma^{\infty}$ for all aqueous systems investigated in this study is $2 \%$ for the m-AD model, and the corresponding AAD in $\gamma^{\infty}$ unit is $7 \%$. The calculated infinite dilution activity coefficients from the m-AD model are comparable to those from the MOSCED, SPACE, PDD, LSER or the modified UNIFAC model. The m-AD model shows lower peak deviation than those from other methods. Satisfactory generalized correlation results are also observed for organic solvents other than water. With the generalized parameters, the m-AD model satisfactorily predicts the limiting activity coefficients for other solutes not included in the correlation.
\end{abstract}

(c) 2003 Elsevier B.V. All rights reserved.

Keywords: Activity coefficient; Method of calculation; Gibbs energy

\section{Introduction}

Knowledge of infinite dilution activity coefficients $\left(\gamma^{\infty}\right)$ is important in many practical applications. $\gamma^{\infty}$ values can be used in solvent selection for traditional separation process such as extractive distillation and were recently employed in calculating the solid solubility in supercritical gases and to calculate the critical micelle concentration of surfactant systems $[1,2]$. Extensive applications in commercially important complex polymer solutions like paints and coatings or pharmaceuticals [3,4] make the study of $\gamma^{\infty}$ essential. The focus on aqueous systems is particularly interesting since water is the most commonly used solvent. The $\gamma^{\infty}$ value in aqueous solution describes the behavior of a single solute

\footnotetext{
* Corresponding author. Tel.: +886-2-2366-1661; fax: +886-2-2362-3040.

E-mail address: ypchen@ccms.ntu.edu.tw (Y.-P. Chen).

${ }^{1}$ Present address: Department of Chemical Engineering, Chinese Culture University, Taipei, Taiwan, ROC.
}

completely surrounded by water molecules. To effectively describe this extreme condition, the limiting activity coefficient plays an important role and provides useful information for the phase behavior of dilute solutions involving the maximum non-ideality.

Unique behavior is usually exhibited in the aqueous solutions. As a result, the values of the limiting activity coefficient can be extremely large. For instance, the $\gamma^{\infty}$ value of $n$-nonane in water is in the order of $10^{7}$. Since the accuracy for predicting $\gamma^{\infty}$ values in various mixtures was not adequate, several modified Gibbs energy models or empirical correlation equations have been presented in literature.

Pierotti et al. [5] proposed a generalized equation (PDD model) that empirically correlates the limiting activity coefficient with structure related parameters of the solute and solvent in a mixture. The MOSCED model [6], as an extension of the regular solution model, described $\gamma^{\infty}$ as function of the polarity, hydrocarbon interaction and asymmetry of the solute and solvent molecules. Hait et al. [7] suggested a SPACE model with the solvatochromic scales for solvents 
and solutes. Sherman et al. [8] further presented a predictive LSER model with parameters from chromatographic observations. In addition to these generalized correlation equations, group contribution methods like ASOG and various versions of UNIFAC are capable of predicting $\gamma^{\infty}$ values.

Critical evaluations on the calculation of infinite dilution activity coefficients have been presented in recent literature [9-11]. Generally, the PDD model is the best correlation for highly non-ideal aqueous systems. The absolute average deviation (AAD) from this model is within $5 \%$ in $\ln \gamma^{\infty}$. The MOSCED and SPACE models yielded AAD values for $\gamma^{\infty}$ around $8 \%$ for organic solvents, but larger AAD values up to $70 \%$ for aqueous systems were also reported [7]. The UNIFAC or ASOG group contribution model is used in the prediction of $\gamma^{\infty}$, but the AAD value for aqueous systems might be larger than $30 \%$ in $\gamma^{\infty}$. Recently, Zhang et al. [12,13] introduced mixture-type groups into the UNIFAC model to account for the hydrophobic effect of aqueous mixtures (taking $n$-hexane + water mixture for example, $n$-hexane has $2 \mathrm{CH}_{3}$ and $4 \mathrm{CH}_{2}$ conventional groups and $6 \mathrm{CH}_{2}{ }^{*}$ mixture-type groups), and the AAD value was improved to $10 \%$ in $\gamma^{\infty}$. For engineering applications on aqueous systems, an easy and generalized correlation method to evaluate $\gamma^{\infty}$ with better accuracy is still demanding. This improvement is accomplished by incorporating a theoretically based activity coefficient model.

Quasi-chemical and local composition lattice models were employed for calculating the non-ideality of fluid mixtures. Aranovich and Donohue recently developed a lattice-based model (AD model) [14] that expressed the internal energy of mixture in terms of the local composition and the interchange energy. Compared to other theories, the AD model yielded better agreement with molecular simulation data, especially at infinite dilution or high density conditions. Based on the AD model, a modified expression for the excess Gibbs energy ( $\mathrm{m}$-AD model) was derived in this study with an improved expression for the local composition. This $\mathrm{m}-\mathrm{AD}$ model was employed in our generalized correlation of infinite dilution activity coefficients of aqueous and organic mixtures. Comparisons of the calculated $\ln \gamma^{\infty}$ values from the $\mathrm{m}-\mathrm{AD}$ and other models are presented. The prediction of $\ln \gamma^{\infty}$ from the m-AD model for systems not included in the correlation is also demonstrated.

\section{Method of calculation}

Based on the previous work of Aranovich and Donohue (AD model) [14], a modified Gibbs energy model (m-AD model) for a binary mixture was employed in this study for calculating infinite dilution activity coefficients. The original AD model considered the exchange equilibrium of molecule $\mathrm{A}$ at a three-dimensional coordinate $(i, j, k)$ with another molecule B from an infinite distance:

$\mathrm{A}_{i, j, k}+\mathrm{B}_{\infty} \rightarrow \mathrm{B}_{i, j, k}+\mathrm{A}_{\infty}$
At equilibrium, the Gibbs energy change for the above equation is zero:

$\Delta G=\Delta H-T \Delta S=0$

The entropy change was calculated using the number of configurations and the mean field theory. Calculation of the enthalpy change was based on the definition of lattice type. In the AD model, a coordination number of 6 was assumed and the enthalpy term was determined using the Bragg-Williams approximation. Eq. (1) is valid for any $i^{2}+j^{2}+k^{2} \geq 1$. Applying Eqs. (1) and (2), the local compositions were evaluated and thermodynamic properties were determined thereafter. In the previous work, only the molecular distribution in the first shell around a central molecule was considered. The density on the second and subsequent shells was assumed the same as that in the bulk. Substituting the expressions for entropy and enthalpy, the $\mathrm{AD}$ model yielded an equation for the probability $X$ of a site $(1,0,0)$ occupied by a molecule $\mathrm{A}$ around a central molecule A:

$X_{1,0,0}=\frac{X_{\infty}}{\left\{X_{\infty}+\left(1-X_{\infty}\right) \exp \left[-\left(1-X_{\infty}\right) \Delta / k_{\mathrm{B}} T\right]\right\}}$

where $k_{\mathrm{B}}$ is the Boltzmann constant, $X_{\infty}$ the bulk composition of molecule $\mathrm{A}$, and $\Delta$ is the interchange energy between the energy $\varepsilon$ of intermolecular interactions:

$\Delta=2 \varepsilon_{\mathrm{AB}}-\varepsilon_{\mathrm{AA}}-\varepsilon_{\mathrm{BB}}$

A similar equation was developed for a probability $Y_{1,0,0}$, where $\mathrm{B}$ was a neighbor to a central $\mathrm{B}$ molecule. The probability equations determined the local compositions, from which an expression of the internal energy of a lattice fluid mixture was derived. This model agreed well with molecular simulation results of monomer mixtures and polymer solutions [15]. Satisfactory limiting behavior for the infinite dilution internal energy has been demonstrated in comparison with other local composition models like UNIQUAC. The concept of the AD model is extended in this study to correlate the infinite dilution activity coefficients of aqueous and organic systems. For more realistic applications, a modification for the assumption of local composition is proposed. In this $\mathrm{m}-\mathrm{AD}$ model, the local densities are interrelated with each other via the distance from the central molecule by an inverse-sixth power law. For example, $X_{1,1,0}$ is not equal to the bulk density in the m-AD model, but is related to $X_{1,0,0}$ by:

$\frac{X_{1,1,0}}{X_{1,0,0}}=\left(\frac{\sqrt{2} d}{d}\right)^{-6}=(\sqrt{2})^{-6}$

where $d$ is the dimension of a lattice site. This assumption is in accordance with the physical meaning of radial distribution function. In practice, we observed from our calculations that the correspondingly derived Gibbs energy model yields satisfactory correlation results not only for $\ln \gamma^{\infty}$, but also for vapor-liquid and liquid-liquid equilibria. It is 
also assumed that the local density for all sites on the same shell occupied by molecule A is the same. Following the similar procedures as in the AD model, the local density $X_{1,0,0}$ in the m-AD model is written as:

$$
\begin{aligned}
& X_{1,0,0} \\
& \quad=\frac{X_{\infty}}{\left\{X_{\infty}+\left(1-X_{\infty}\right) \exp \left[-\left(1+c X_{1,0,0}-6 X_{\infty}\right) \Delta / k_{\mathrm{B}} T\right]\right\}}
\end{aligned}
$$

where $c$ equals $2^{-6}+4(\sqrt{2})^{-6}$, and the bulk concentration $X_{\infty}$ is taken as the mole fraction $x_{\mathrm{A}}$. The local composition expression $Y_{1,0,0}$ as the probability of finding a molecule $B$ in the first shell around a central molecule $\mathrm{B}$, is written in a similar way as Eq. (6) but with a bulk composition of $\left(1-X_{\infty}\right)$ or $x_{\mathrm{B}}$. The local compositions in the m-AD model were solved by a numerical method.

The total internal energy of a lattice fluid mixture is expressed as:

$U=\frac{1}{2} z N_{\mathrm{A}} \varepsilon_{\mathrm{AA}}+\frac{1}{2} z N_{\mathrm{B}} \varepsilon_{\mathrm{BB}}+\frac{1}{2} N_{\mathrm{AB}} \Delta$

where $N_{\mathrm{A}}$ or $N_{\mathrm{B}}$ is the total number of molecules of component $\mathrm{A}$ or $\mathrm{B}$, respectively. $N_{\mathrm{AB}}$ is the number of $\mathrm{A}-\mathrm{B}$ pairs and is obtained from the coordination number $z$ ( $z$ equals 6 in the m-AD model) and the local compositions:

$N_{\mathrm{AB}}=\frac{z}{2}\left[N_{\mathrm{A}}\left(1-X_{1,0,0}\right)+N_{\mathrm{B}}\left(1-Y_{1,0,0}\right)\right]$

To account for the effect on molecular size and shape, the bulk composition $X_{\infty}$ in Eq. (6) is replaced by the surface area fraction $\theta_{\mathrm{A}}$. In a similar way, $\left(1-X_{\infty}\right)$ is replaced by $\theta_{\mathrm{B}}$. Substituting these local composition expressions into Eq. (7) and treating $N_{\mathrm{A}}$ and $N_{\mathrm{B}}$ as the total surface area, the molar excess internal energy is then evaluated after some simplification as:

$$
\begin{aligned}
u^{\mathrm{E}}= & \frac{z}{4}\left\{x_{\mathrm{A}} q_{\mathrm{A}} \Delta_{\mathrm{AB}} \frac{\theta_{\mathrm{B}} \exp \left[-\left(1+c X_{1,0,0}-6 \theta_{\mathrm{A}}\right) \Delta_{\mathrm{AB}} / R T\right]}{\theta_{\mathrm{A}}+\theta_{\mathrm{B}} \exp \left[-\left(1+c X_{1,0,0}-6 \theta_{\mathrm{A}}\right) \Delta_{\mathrm{AB}} / R T\right]}\right. \\
& \left.+x_{\mathrm{B}} q_{\mathrm{B}} \Delta_{\mathrm{BA}} \frac{\theta_{\mathrm{A}} \exp \left[-\left(1+c Y_{1,0,0}-6 \theta_{\mathrm{B}}\right) \Delta_{\mathrm{BA}} / R T\right]}{\theta_{\mathrm{B}}+\theta_{\mathrm{A}} \exp \left[-\left(1+c Y_{1,0,0}-6 \theta_{\mathrm{B}}\right) \Delta_{\mathrm{BA}} / R T\right]}\right\}
\end{aligned}
$$

The two interchange energy terms $\Delta_{\mathrm{AB}}$ and $\Delta_{\mathrm{BA}}$ in Eq. (9) indicate that the local intermolecular force between unlike pairs is in principle not the same for A or B as the central molecule. To determine the molar excess Gibbs energy, the Gibbs-Helmholtz relation is employed:

$u^{\mathrm{E}} \approx h^{\mathrm{E}}=\left[\frac{\partial\left(g^{\mathrm{E}} / T\right)}{\partial(1 / T)}\right]_{V, x}$

Upon integrating Eq. (10) from an infinite temperature limit to $T$, the molar excess Gibbs energy is found:

$$
\frac{g^{\mathrm{E}}}{R T}=\left(\frac{g^{\mathrm{E}, \mathrm{C}}}{R T}\right)_{T=\infty}+\frac{1}{R} \int_{0}^{1 / T} u^{\mathrm{E}} \mathrm{d}\left(\frac{1}{T}\right)
$$

The first term on the right hand side of Eq. (11) is the combinatorial contribution at a high temperature limit where an athermal mixture is assumed. The Guggenheim equation for an athermal mixture of molecules with arbitrary size and shape is applied:

$$
\begin{aligned}
\left(\frac{g^{\mathrm{E}, \mathrm{C}}}{R T}\right)= & x_{\mathrm{A}} \ln \frac{\phi_{\mathrm{A}}^{\prime}}{x_{\mathrm{A}}}+x_{\mathrm{B}} \ln \frac{\phi_{\mathrm{B}}^{\prime}}{x_{\mathrm{B}}} \\
& -5\left(x_{\mathrm{A}} q_{\mathrm{A}} \ln \frac{\phi_{\mathrm{A}}}{\theta_{\mathrm{A}}}+x_{\mathrm{B}} q_{\mathrm{B}} \ln \frac{\phi_{\mathrm{B}}}{\theta_{\mathrm{B}}}\right)
\end{aligned}
$$

where $\phi^{\prime}, \phi$, and $\theta$ are the fractions of the volume $r$ and surface area $q$, respectively:

$\theta=\frac{x_{i} q_{i}}{\sum x_{i} q_{i}}$

$\phi=\frac{x_{i} r_{i}}{\sum x_{i} r_{i}}$

$\phi^{\prime}=\frac{x_{i} r_{i}^{3 / 4}}{\sum x_{i} r_{i}^{3 / 4}}$

The combinatorial part is the same as in the modified UNIFAC (m-UNIFAC) model [16]. Since this equation is satisfactorily examined for athermal solutions, it is directly applied in this study. The residual contribution to $g^{\mathrm{E}}$ is determined from the integration term of Eq. (11):

$$
\begin{aligned}
\frac{g^{\mathrm{E}, \mathrm{R}}}{R T}= & \frac{-z}{4}\left\{x_{\mathrm{A}} q_{\mathrm{A}} \frac{1}{1+c X_{1,0,0}-6 \theta_{\mathrm{A}}}\right. \\
& \times \ln \left\{\theta_{\mathrm{A}}+\theta_{\mathrm{B}} \exp \left[-\left(1+c X_{1,0,0}-6 \theta_{\mathrm{A}}\right) \frac{\Delta_{\mathrm{AB}}}{R T}\right]\right\} \\
& +x_{\mathrm{B}} q_{\mathrm{B}} \frac{1}{1+c Y_{1,0,0}-6 \theta_{\mathrm{B}}} \\
& \left.\times \ln \left\{\theta_{\mathrm{B}}+\theta_{\mathrm{A}} \exp \left[-\left(1+c Y_{1,0,0}-6 \theta_{\mathrm{B}}\right) \frac{\Delta \mathrm{BA}}{R T}\right]\right\}\right\}
\end{aligned}
$$

Finally, the activity coefficient of the solute B is obtained. Its limiting equation is evaluated as $x_{\mathrm{B}}$ approaches to zero:

$$
\begin{aligned}
\ln \gamma_{\mathrm{B}}^{\infty}= & \ln \gamma_{\mathrm{B}}^{\infty, \mathrm{C}}+\ln \gamma_{\mathrm{B}}^{\infty, \mathrm{R}} \\
= & \left\{\left[\ln \left(\frac{r_{\mathrm{B}}}{r_{\mathrm{A}}}\right)^{0.75}+1-\left(\frac{r_{\mathrm{B}}}{r_{\mathrm{A}}}\right)^{0.75}\right]\right. \\
& \left.-5 q_{\mathrm{B}}\left(\ln \frac{r_{\mathrm{B}} q_{\mathrm{A}}}{r_{\mathrm{A}} q_{\mathrm{B}}}+1-\frac{r_{\mathrm{B}} q_{\mathrm{A}}}{r_{\mathrm{A}} q_{\mathrm{B}}}\right)\right\} \\
& -\frac{z}{4} q_{\mathrm{B}}\left\{\frac{1}{c-5}\left\{\exp \left[-(c-5) \frac{\Delta}{R T}\right]-1\right\}-\frac{\Delta}{R T}\right\}
\end{aligned}
$$

At infinite dilution, the solute $B$ is at an infinitesimal concentration and is completely surrounded by the solvent molecule $A$. In such a limiting case, only one kind of unlike intermolecular force is considered, and hence 
$\Delta_{\mathrm{AB}}=\Delta_{\mathrm{BA}}=\Delta$ as shown in Eq. (17). The molecular surface area and volume parameters are known and are taken from Gmehling et al. [16]. The interchange energy $\Delta$ is the only adjustable parameter in this m-AD model. Its optimal value is regressed from the experimental data of each binary pair by minimizing the following objective function:

$\mathrm{obj}=\frac{\sum\left|\ln \gamma_{\mathrm{B}}^{\infty, \exp }-\ln \gamma_{\mathrm{B}}^{\infty, \mathrm{cal}}\right|}{\ln \gamma_{\mathrm{B}}^{\infty, \exp }}$

The calculations of the infinite dilution activity coefficient in aqueous and organic solutions using the m-AD model are presented in this study. The results calculated from the PDD, MOSCED, SPACE, LSER and the m-UNIFAC models [16] are compared with those obtained from the new model.

Table 1

Database of the experimental $\gamma^{\infty}$ values for 2-ketones aqueous solutions at $298.15 \mathrm{~K}$

\begin{tabular}{|c|c|c|c|c|}
\hline Solute & $\gamma^{\infty, \exp }$ & $\begin{array}{l}\text { Experimental } \\
\text { method }\end{array}$ & $\begin{array}{l}\text { Ref. no. in } \\
\text { Table } 1 \text { of } \\
\text { Kojima et al. } \\
{[17]}\end{array}$ & $\begin{array}{l}\gamma^{\infty} \text { in } \\
\text { Sherman } \\
\text { et al. [8] }\end{array}$ \\
\hline \multirow[t]{8}{*}{ 2-Butanone } & 25.6 & HS & 9 & 25.6 \\
\hline & 27.8 & GC & 42 & \\
\hline & 26.0 & HS & 46 & \\
\hline & 27.6 & NSGC & 32 & \\
\hline & 41.2 & LLC & 11 & \\
\hline & 65.7 & LLC & 24 & \\
\hline & 25.3 & GS & 14 & \\
\hline & 26.4 & GC & 56 & \\
\hline \multirow[t]{6}{*}{ Acetone } & 7.01 & HS & 9 & 7.01 \\
\hline & 7.56 & GCR & 42 & \\
\hline & 7.31 & NSGC & 32 & \\
\hline & 21.1 & LLC & 11 & \\
\hline & 61.9 & LLC & 24 & \\
\hline & 7.69 & GC & 56 & \\
\hline \multirow[t]{5}{*}{ 2-Pentanone } & 93.4 & HS & 9 & 93.4 \\
\hline & 98.9 & GCR & 42 & \\
\hline & 102.0 & NSGC & 32 & \\
\hline & 102.5 & LLC & 11 & \\
\hline & 135.1 & LLC & 24 & \\
\hline \multirow[t]{2}{*}{ 2-Hexanone } & 355.7 & HS & 9 & 356 \\
\hline & 329.1 & LLC & 11 & \\
\hline \multirow[t]{3}{*}{ 2-Heptanone } & 1397 & HS & 9 & 1400 \\
\hline & 1055 & LLC & 11 & \\
\hline & 882.2 & LLC & 24 & \\
\hline \multirow[t]{2}{*}{ 2-Nonanone } & 16290 & KHW & 37 & 16300 \\
\hline & 24800 & KGW & 2 & \\
\hline
\end{tabular}

HS: headspace chromatography; GCR: gas-liquid chromatography with gas phase correction; GC: gas-liquid chromatography with no gas phase correction; NSGC: non-steady state gas chromatography; LLC: liquid-liquid chromatography; GS: gas-stripping; KHW: hexadecanewater partition coefficient indirect method; KGW: gas-water partition coefficient indirect method.

\section{Results and discussion}

Various measuring methods yield different $\gamma^{\infty}$ experimental data. Kojima et al. [17] presented a database for $\gamma^{\infty}$ and a review of experimental techniques. Taking 2-butanone aqueous solution at $298.15 \mathrm{~K}$ for example, there are eight data points from different measurement methods listed by Kojima et al. These data are shown also in Table 1. Among them two values are quite large while the rest are within $5 \%$ from their mean value. In the previous development of the LSER model, Sherman et al. [8] chose the experimental $\gamma^{\infty}$ value of 25.6. In our correlation, we selected the experimental data that appeared in both articles of Kojima et al. [17] and Sherman et al. [8]. The similar choices for other 2-ketone aqueous solutions are also presented in Table 1. In this study, measured $\gamma^{\infty}$ data from a same source for a series of solutes were preferred in our correlation of homologous components.

The m-AD excess Gibbs energy model derived in this study is employed to correlate infinite dilution activity coefficients in the aqueous and organic solutions. Only one parameter $\Delta$ is required for each binary mixture, and its value is obtained from data regression. It is observed that the $\Delta$ values vary with the structures of the solutes. For each homologous series, $\Delta$ values show a strong correlation with the refractive index of the pure solutes. A typical plot of $\Delta$ against the refractive index is shown in Fig. 1 for the aqueous solutions of 1-alcohols (from ethanol to 1-heptanol) and nitriles (from acetonitrile to hexanenitrile). A linear relationship is found which indicates the feasibility for predictive calculations. Accordingly, a relatively simple correlation equation is proposed:

$\Delta(\mathrm{kJ} / \mathrm{mol})=\alpha+\beta \times \mathrm{RI}$

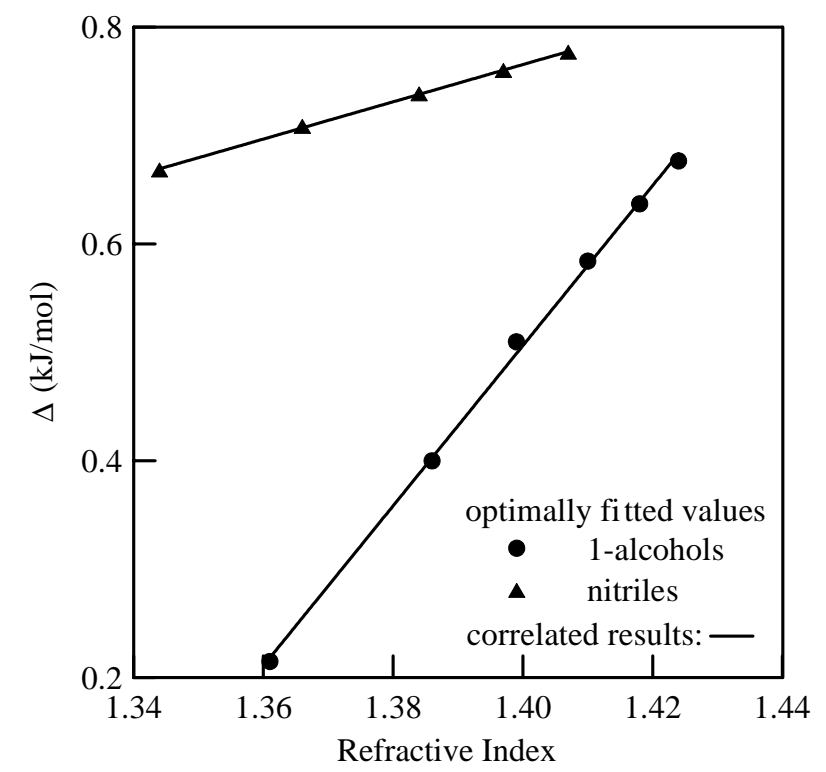

Fig. 1. Relationship between the interchange energy parameter and the refractive index of pure solutes in aqueous systems. 
Table 2

Experimental and calculated $\ln \gamma^{\infty}$ values for aqueous systems in this study

\begin{tabular}{|c|c|c|c|c|c|c|}
\hline Family of solute & Solute (B) & RI & $\ln \gamma_{\mathrm{B}}^{\infty, \exp }$ & $\ln \gamma_{\mathrm{B}}^{\infty, \text { cal }}$ & $\operatorname{AAD}^{\mathrm{a}}(\%)$ & Data ref. \\
\hline \multirow[t]{5}{*}{$n$-Acids } & Acetic acid & 1.372 & 1.065 & 1.065 & 0.00 & [17]-T1-72 \\
\hline & Butyric acid & 1.398 & 3.968 & 3.274 & 17.50 & [17]-T1-72 \\
\hline & Valeric acid & 1.408 & 4.844 & 4.712 & 2.72 & [8]-T5-11 \\
\hline & Hexanoic acid & 1.417 & 6.400 & 6.400 & 0.00 & [8]-T5-11 \\
\hline & Heptanoic acid & 1.423 & 7.833 & 8.060 & 2.90 & [17]-T2-9 \\
\hline \multirow[t]{6}{*}{ 1-Alcohols } & Ethanol & 1.361 & 1.319 & 1.347 & 2.12 & [17]-T1-9 \\
\hline & 1-Propanol & 1.386 & 2.592 & 2.592 & 0.00 & [17]-T1-9 \\
\hline & 1-Butanol & 1.399 & 3.916 & 3.768 & 3.77 & [17]-T1-9 \\
\hline & 1-Pentanol & 1.410 & 5.289 & 5.142 & 2.79 & [17]-T1-9 \\
\hline & 1-Hexanol & 1.418 & 6.683 & 6.558 & 1.88 & [17]-T1-9 \\
\hline & 1-Heptanol & 1.425 & 8.093 & 7.995 & 1.21 & [17]-T1-42 \\
\hline \multirow[t]{5}{*}{ Aldehydes } & Acetaldehyde & 1.332 & 1.371 & 1.371 & 0.00 & [17]-T1-42 \\
\hline & Propanal & 1.362 & 2.567 & 2.615 & 1.87 & [17]-T1-9 \\
\hline & Butanal & 1.379 & 3.884 & 3.884 & 0.00 & [17]-T1-9 \\
\hline & Pentanal & 1.394 & 5.395 & 5.336 & 1.10 & [17]-T1-9 \\
\hline & Hexanal & 1.404 & 6.701 & 6.787 & 1.29 & [17]-T1-9 \\
\hline \multirow[t]{10}{*}{$n$-Alkanes } & Ethane & 1.038 & 6.558 & 6.558 & 0.00 & {$[18]$} \\
\hline & Propane & 1.290 & 8.349 & 7.608 & 8.88 & [18] \\
\hline & Butane & 1.333 & 9.995 & 9.250 & 7.45 & [18] \\
\hline & Pentane & 1.358 & 11.528 & 10.928 & 5.20 & [18] \\
\hline & Hexane & 1.375 & 13.055 & 12.615 & 3.37 & [18] \\
\hline & Heptane & 1.388 & 14.553 & 14.308 & 1.69 & [18] \\
\hline & Octane & 1.397 & 15.998 & 16.004 & 0.04 & [18] \\
\hline & Nonane & 1.405 & 17.700 & 17.700 & 0.00 & [18] \\
\hline & Decane & 1.412 & 19.219 & 19.397 & 0.92 & [18] \\
\hline & Dodecane & 1.422 & 21.699 & 22.796 & 5.06 & [18] \\
\hline \multirow[t]{6}{*}{ 1-Alkenes } & Propene & 1.357 & 6.945 & 6.886 & 0.84 & {$[18]$} \\
\hline & Butene & 1.369 & 8.399 & 8.465 & 0.78 & [18] \\
\hline & Pentene & 1.371 & 10.179 & 10.179 & 0.00 & [18] \\
\hline & Hexene & 1.388 & 11.447 & 11.483 & 0.32 & [18] \\
\hline & Heptene & 1.400 & 12.802 & 12.802 & 0.00 & [18] \\
\hline & Octene & 1.409 & 14.652 & 14.143 & 3.47 & {$[18]$} \\
\hline \multirow[t]{6}{*}{$n$-Alkyl acetates } & Methyl acetate & 1.361 & 3.118 & 3.118 & 0.00 & [17]-T1-9 \\
\hline & Ethyl acetate & 1.372 & 4.179 & 4.197 & 0.42 & [17]-T1-9 \\
\hline & Propyl acetate & 1.384 & 5.489 & 5.434 & 1.01 & [17]-T1-9 \\
\hline & Butyl acetate & 1.392 & 6.702 & 6.662 & 0.60 & [17]-T1-9 \\
\hline & Pentyl acetate & 1.402 & 8.081 & 8.081 & 0.00 & [17]-T1-9 \\
\hline & Hexyl acetate & 1.409 & 9.433 & 9.474 & 0.44 & [17]-T1-9 \\
\hline \multirow[t]{6}{*}{$n$-Alkyl benzene } & Benzene & 1.501 & 7.786 & 7.786 & 0.00 & [19] \\
\hline & Toluene & 1.497 & 9.190 & 8.659 & 5.78 & [19] \\
\hline & Ethylbenzene & 1.496 & 10.463 & 10.626 & 1.56 & [19] \\
\hline & Propylbenzene & 1.492 & 11.369 & 11.475 & 0.93 & [19] \\
\hline & Butylbenzene & 1.490 & 13.175 & 12.549 & 4.75 & [19] \\
\hline & Pentylbenzene & 1.488 & 13.545 & 13.545 & 0.00 & [19] \\
\hline \multirow[t]{7}{*}{ Alkyl ethers } & Di-ethyl ether & 1.353 & 4.697 & 4.697 & 0.00 & [17]-T1-29 \\
\hline & Di-propyl ether & 1.381 & 7.747 & 7.624 & 1.58 & [17]-T1-38 \\
\hline & Di-isopropyl ether & 1.368 & 6.443 & 6.991 & 8.51 & [17]-T1-38 \\
\hline & Di-butyl ether & 1.399 & 10.762 & 10.762 & 0.00 & [17]-T1-38 \\
\hline & Methyl propyl ether & 1.357 & 4.883 & 4.835 & 0.98 & [8]-T5-11 \\
\hline & Methyl butyl ether & 1.374 & 6.303 & 6.339 & 0.57 & [8]-T5-11 \\
\hline & Ethyl propyl ether & 1.370 & 5.549 & 6.160 & 11.01 & [8]-T5-11 \\
\hline \multirow[t]{7}{*}{ Bromides } & Bromoethane & 1.424 & 6.521 & 6.596 & 1.12 & [17]-T1-38 \\
\hline & 1-Bromopropane & 1.434 & 7.955 & 7.955 & 0.00 & [17]-T1-38 \\
\hline & 1-Bromobutane & 1.440 & 9.413 & 9.322 & 0.96 & [17]-T1-38 \\
\hline & 1-Bromopentane & 1.444 & 11.100 & 10.683 & 3.76 & [8]-T5-13 \\
\hline & Dibromomethane & 1.542 & 6.745 & 6.474 & 4.02 & {$[17]-\mathrm{T} 1-41$} \\
\hline & 1,2-Dibromoethane & 1.539 & 7.836 & 7.768 & 0.87 & [8]-T5-11 \\
\hline & 1,2-Dibromopropane & 1.520 & 8.963 & 9.249 & 3.19 & [8]-T5-13 \\
\hline
\end{tabular}


Table 2 (Continued)

\begin{tabular}{|c|c|c|c|c|c|c|}
\hline Family of solute & Solute (B) & RI & $\ln \gamma_{\mathrm{B}}^{\infty, \exp }$ & $\ln \gamma_{\mathrm{B}}^{\infty, \mathrm{cal}}$ & $\operatorname{AAD}^{\mathrm{a}}(\%)$ & Data ref. \\
\hline & 1,3-Dibromopropane & 1.523 & 8.805 & 9.211 & 4.60 & [8]-T5-11 \\
\hline & Tribromomethane & 1.596 & 8.126 & 8.126 & 0.00 & [17]-T1-41 \\
\hline \multirow[t]{14}{*}{ Chlorides } & Chloroethane & 1.370 & 5.976 & 5.834 & 2.38 & {$[8]-\mathrm{T} 5-13$} \\
\hline & 1-Chloropropane & 1.389 & 7.466 & 7.392 & 0.99 & [17]-T1-38 \\
\hline & 1-Chlorobutane & 1.402 & 8.937 & 8.937 & 0.00 & [17]-T1-38 \\
\hline & 1-Chloropentane & 1.412 & 10.376 & 10.483 & 1.03 & [17]-T1-38 \\
\hline & 1-Chlorohexane & 1.420 & 11.855 & 12.024 & 1.42 & [17]-T1-38 \\
\hline & Dichloromethane & 1.424 & 5.533 & 5.743 & 3.79 & [17]-T1-38 \\
\hline & 1,1-Dichloroethane & 1.416 & 6.985 & 7.421 & 6.24 & [17]-T1-4 \\
\hline & 1,2-Dichloroethane & 1.445 & 6.463 & 6.169 & 4.55 & [17]-T1-38 \\
\hline & 1,2-Dichloropropane & 1.439 & 7.754 & 7.799 & 0.58 & [17]-T1-41 \\
\hline & 1,3-Dichloropropane & 1.449 & 7.741 & 7.741 & 0.00 & [8]-T5-11 \\
\hline & Trichloromethane & 1.446 & 6.806 & 6.746 & 0.88 & [17]-T1-38 \\
\hline & 1,1,1-Trichloroethane & 1.438 & 8.683 & 8.545 & 1.59 & [17]-T1-38 \\
\hline & 1,1,2-Trichloroethane & 1.471 & 7.313 & 7.824 & 6.98 & [17]-T1-4 \\
\hline & 1,2,3-Trichloro-propane & 1.483 & 8.369 & 8.242 & 1.51 & {$[8]-\mathrm{T} 5-13$} \\
\hline \multirow[t]{4}{*}{ Cycloalkanes } & Cyclopentane & 1.407 & 10.123 & 10.123 & 0.00 & {$[8]-\mathrm{T} 5-11$} \\
\hline & Cyclohexane & 1.426 & 11.330 & 11.330 & 0.00 & {$[8]-\mathrm{T} 5-15$} \\
\hline & Cycloheptane & 1.445 & 12.112 & 12.365 & 2.09 & {$[8]-\mathrm{T} 5-11$} \\
\hline & Cyclooctane & 1.459 & 13.579 & 13.432 & 1.08 & [8]-T5-11 \\
\hline \multirow[t]{6}{*}{ 2-Ketones } & Acetone & 1.359 & 1.947 & 2.004 & 2.95 & [17]-T1-9 \\
\hline & 2-Butanone & 1.379 & 3.243 & 3.243 & 0.00 & [17]-T1-9 \\
\hline & 2-Pentanone & 1.390 & 4.537 & 4.418 & 2.61 & [17]-T1-9 \\
\hline & 2-Hexanone & 1.401 & 5.874 & 5.821 & 0.90 & [17]-T1-9 \\
\hline & 2-Heptanone & 1.409 & 7.242 & 7.242 & 0.00 & [17]-T1-9 \\
\hline & 2-Nonanone & 1.421 & 9.698 & 10.245 & 5.63 & [17]-T1-37 \\
\hline \multirow[t]{5}{*}{ Nitriles } & Acetonitrile & 1.344 & 2.407 & 2.407 & 0.00 & [17]-T1-9 \\
\hline & Propionitrile & 1.366 & 3.564 & 3.550 & 0.40 & [17]-T1-9 \\
\hline & Butyronitrile & 1.384 & 4.769 & 4.760 & 0.20 & [17]-T1-9 \\
\hline & Valeronitrile & 1.397 & 5.996 & 5.999 & 0.06 & [17]-T1-9 \\
\hline & Hexanenitrile & 1.407 & 7.245 & 7.245 & 0.00 & {$[17]-\mathrm{T} 1-9$} \\
\hline \multirow[t]{3}{*}{ Nitro compounds } & Nitromethane & 1.381 & 3.453 & 3.453 & 0.00 & [17]-T1-9 \\
\hline & Nitroethane & 1.392 & 4.484 & 4.271 & 4.74 & [17]-T1-9 \\
\hline & Nitropropane & 1.402 & 5.701 & 5.701 & 0.00 & [17]-T1-9 \\
\hline \multirow[t]{3}{*}{ Tetrachlorides } & Tetrachloromethane & 1.460 & 9.642 & 9.642 & 0.00 & [17]-T1-37 \\
\hline & 1,1,1,2-Tetrachloro-ethane & 1.482 & 9.095 & 9.148 & 0.58 & [17]-T1-41 \\
\hline & $1,1,2,2$-Tetrachloro-ethane & 1.494 & 8.152 & 8.152 & 0.00 & [8]-T5-1 \\
\hline
\end{tabular}

Data ref:: For instance, [8]-T5-11 represents the reference 11 in Table 5 of Sherman et al. [8], and [17]-T1-72 represents the reference 72 in Table 1 of Kojima et al. [17].

$$
{ }^{\mathrm{a}} \operatorname{AAD}(\%)=\frac{100}{\mathrm{NP}} \times \sum_{i}^{\mathrm{NP}}\left|\frac{\ln \gamma_{\mathrm{B}, i}^{\infty, \exp }-\ln \gamma_{\mathrm{B}, i}^{\infty, \mathrm{cal}}}{\ln \gamma_{\mathrm{B}, i}^{\infty, \exp }}\right| \text {. }
$$

where RI is the refractive index of the pure solute molecule, and $\alpha$ and $\beta$ are two constants for each homologous series of solutes. We have found that it is better to correlate $\Delta$ with $\mathrm{RI}$ than the carbon number for a homologous series, since a superior linear relationship was observed.

Over 90 binary aqueous mixtures are included in this study for the calculation of limiting activity coefficients at $298.15 \mathrm{~K}$. From nonpolar hydrocarbons, moderately polar esters to strong polar alcohols, 15 families of solute molecules are employed. The refractive index of solutes, experimental and calculated $\ln \gamma^{\infty}$ values, and the calculation deviation for each system in this study are listed in Table 2. With two generalized parameters for each homologous series of solutes, the overall deviation for the 95 binary sys- tems is $2 \%$ in $\ln \gamma^{\infty}$. The corresponding deviation in $\gamma^{\infty}$ is $7 \%$ from the m-AD model. The optimal $\alpha$ and $\beta$ parameters and the accuracy of calculated $\ln \gamma^{\infty}$ results using the $\mathrm{m}$-AD model are listed in Table 3.

To compare the generalized calculation results from the $\mathrm{m}$-AD model with those from literature, the MOSCED, SPACE, PDD, LSER and the m-UNIFAC [16] models are also investigated. The calculated deviations for $\ln \gamma^{\infty}$ from various methods are listed in Table 3. Among the five literature methods, the PDD model shows a lower overall $\mathrm{AAD}$ of $2.67 \%$. Some parameters in the PDD model were unavailable like for systems of alkenes, and 2-3 adjustable parameters for these homologous series were regressed in this study. The overall deviation from the PDD correlation 
Table 3

Comparison of the calculated $\ln \gamma^{\infty}$ values of aqueous mixtures at $298.15 \mathrm{~K}$ from various models

\begin{tabular}{|c|c|c|c|c|c|c|c|c|c|}
\hline \multirow[t]{2}{*}{ Family of solutes } & \multirow[t]{2}{*}{$\begin{array}{l}\text { Data points } \\
\text { (NP) }\end{array}$} & \multicolumn{2}{|c|}{$\begin{array}{l}\text { Parameters of the } \\
\text { m-AD model }\end{array}$} & \multicolumn{6}{|l|}{$\mathrm{AAD}^{\mathrm{a}}(\%)$} \\
\hline & & $\alpha$ & $\beta$ & MOSCED & SPACE & PDD & LSER & m-UNIFAC & $\mathrm{m}-\mathrm{AD}$ \\
\hline$n$-Acids & 5 & -10.173 & 7.684 & N.A. & N.A. & 4.44 & 49.9 & 13.1 & 5.25 \\
\hline 1-Alcohols & 6 & -9.473 & 7.123 & 10.2 & 22.4 & 4.28 & 11.2 & 9.17 & 1.96 \\
\hline Aldehydes & 5 & -4.604 & 3.817 & N.A. & N.A. & 4.65 & 12.8 & 8.05 & 0.85 \\
\hline n-Alkanes & 10 & 1.431 & -0.272 & 1.87 & 14.5 & 1.25 & 3.29 & 32.6 & 3.26 \\
\hline 1-Alkenes & 6 & 2.771 & -1.261 & 2.38 & 5.64 & 2.69 & 1.63 & 45.4 & 0.90 \\
\hline$n$-Alkyl acetates & 6 & -3.097 & 2.758 & 6.56 & 4.41 & 4.98 & 2.15 & 3.64 & 0.41 \\
\hline$n$-Alkyl benzene & 6 & -16.520 & 11.753 & 2.46 & 11.1 & 1.13 & 2.43 & 2.07 & 2.17 \\
\hline Alkyl ethers & 7 & -3.595 & 3.145 & N.A. & 6.53 & 4.27 & 3.73 & 12.4 & 3.23 \\
\hline Bromides & 9 & 1.953 & -0.711 & 5.59 & N.A. & 0.26 & 2.83 & 21.1 & 2.06 \\
\hline Chlorides & 14 & 1.609 & -0.430 & 6.62 & 44.6 & 0.75 & 1.46 & 10.8 & 2.28 \\
\hline Cycloalkanes & 4 & 3.421 & -1.720 & 2.12 & 7.07 & 0.77 & 5.99 & 42.2 & 0.79 \\
\hline 2-Ketones & 6 & -6.774 & 5.297 & 3.85 & 19.0 & 3.09 & 5.70 & 6.26 & 2.02 \\
\hline Nitriles & 5 & -1.657 & 1.730 & 6.57 & 15.0 & 1.89 & 1.65 & 2.36 & 0.13 \\
\hline Nitro compounds & 3 & -7.824 & 6.073 & 4.66 & 2.51 & N.A. & 6.00 & 4.71 & 1.58 \\
\hline Tetrachlorides & 3 & 12.075 & -7.490 & 1.88 & 27.4 & N.A. & 1.21 & 11.7 & 0.19 \\
\hline Grand & 95 & & & 4.93 & 13.9 & 2.67 & 6.98 & 15.7 & 2.00 \\
\hline
\end{tabular}

a $\operatorname{AAD}(\%)=\frac{100}{\mathrm{NP}} \times \sum_{i}^{\mathrm{NP}}\left|\frac{\ln \gamma_{\mathrm{B}, i}^{\infty, \exp }-\ln \gamma_{\mathrm{B}, i}^{\infty, \text { cal }}}{\ln \gamma_{\mathrm{B}, i}^{\infty, \mathrm{exp}}}\right|$.

is slightly larger than that from the m-AD model. The MOSCED and SPACE are widely referred predictive models for non-aqueous mixtures, but they do not have sufficient parameters for aqueous systems calculations [6,7]. In this study, we have regressed six or seven parameters for these two models from the experimental data points. It is shown in Table 3 that for many systems, both MOSCED and SPACE models give satisfactory results that are within experimental accuracy. The peak deviations in some systems, however, are larger than those from the m-AD model. The m-UNIFAC model is predictive in nature, however, it shows a larger AAD than that from MOSCED. The predictive LSER model yields comparable results to those from MOSCED. When the LSER model is used for the strongly polar acids or the m-UNIFAC model is employed for the nonpolar hydrocarbons, a peak AAD for $\ln \gamma^{\infty}$ up to $40 \%$ is observed. Fig. 2 presents a comparison for aqueous mixtures of $n$-acids. In this case, the m-AD and the PDD models show good agreement with experimental data. For this strongly polar solute series, the LSER model presents relatively larger deviations. The correlative $\mathrm{m}-\mathrm{AD}$ model requires more parameters than the predictive methods. The parameters in the m-AD model, however, can be generalized for each solute family that result in the minimum overall error for aqueous systems in this study. It can be regarded as a simple and reliable model for engineering applications.

The $\mathrm{m}$-AD model is examined for the infinite dilution activity coefficient calculations of non-aqueous systems. A list of systems investigated in this study for various solutes in polar solvents is shown in Table 4 . The $\Delta$ parameter for a homologous series of solutes in a specific solvent is again a linear function of the refractive index of the pure solute, as written in Eq. (19). The numerical values of parameters for $\alpha$ and $\beta$ for these non-aqueous systems are listed in Table 5 . A plot of the optimal $\Delta$ values against the refractive index of $n$-alkane solutes in the solvents acetic acid and 1-propanol is shown in Fig. 3. For the non-aqueous solvents, the calculated errors from the m-AD model are compared with those from the MOSCED, SPACE and the m-UNIFAC models, as demonstrated in Table 5. The SPACE model yielded large deviations if its original parameters were used. Three constants in the scale factors of SPACE were taken as adjustable

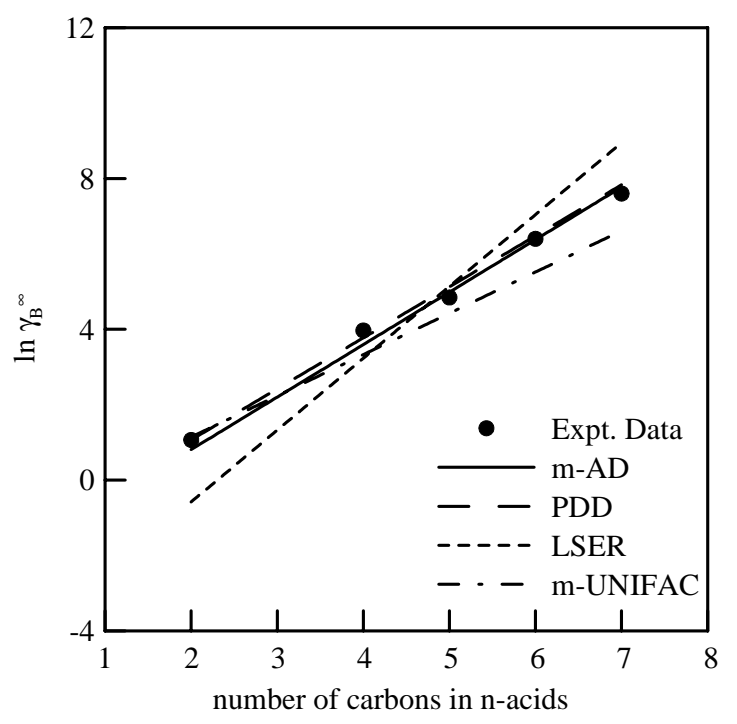

Fig. 2. Comparison of the calculated infinite dilution activity coefficients from various methods for $n$-acids (B) aqueous mixtures at $298.15 \mathrm{~K}$. 
Table 4

Experimental and calculated $\ln \gamma^{\infty}$ values for non-aqueous systems in this study

\begin{tabular}{|c|c|c|c|c|c|c|}
\hline Solvent & Family of solute & Solute (B) & $\ln \gamma_{\mathrm{B}}^{\infty, \exp }$ & $\ln \gamma_{\mathrm{B}}^{\infty, \mathrm{cal}}$ & $\mathrm{AAD}^{\mathrm{a}}(\%)$ & Data ref. \\
\hline \multirow[t]{5}{*}{ Ethanol } & \multirow[t]{5}{*}{$n$-Alkanes } & Pentane & 2.052 & 2.149 & 4.73 & [20] \\
\hline & & Hexane & 2.360 & 2.360 & 0.01 & [20] \\
\hline & & Heptane & 2.570 & 2.570 & 0.00 & [20] \\
\hline & & Octane & 2.780 & 2.780 & 0.00 & [20] \\
\hline & & Nonane & 2.978 & 2.990 & 0.40 & {$[20]$} \\
\hline \multirow[t]{5}{*}{ 1-Propanol } & \multirow[t]{5}{*}{$n$-Alkanes } & Pentane & 1.631 & 1.631 & 0.00 & [20] \\
\hline & & Hexane & 1.907 & 1.844 & 3.28 & [20] \\
\hline & & Heptane & 2.068 & 2.054 & 0.67 & [20] \\
\hline & & Octane & 2.253 & 2.262 & 0.38 & [20] \\
\hline & & Nonane & 2.471 & 2.471 & 0.00 & [20] \\
\hline \multirow[t]{5}{*}{ Acetone } & \multirow[t]{5}{*}{$n$-Alkanes } & Pentane & 1.637 & 1.681 & 2.68 & [20] \\
\hline & & Hexane & 1.967 & 1.908 & 3.00 & [20] \\
\hline & & Heptane & 2.134 & 2.134 & 0.00 & [20] \\
\hline & & Octane & 2.359 & 2.359 & 0.00 & {$[20]$} \\
\hline & & Nonane & 2.554 & 2.585 & 1.23 & [20] \\
\hline \multirow[t]{5}{*}{ 2-Butanone } & \multirow[t]{5}{*}{$n$-Alkanes } & Pentane & 1.221 & 1.221 & 0.00 & {$[20]$} \\
\hline & & Hexane & 1.409 & 1.367 & 2.94 & {$[20]$} \\
\hline & & Heptane & 1.440 & 1.511 & 4.98 & {$[20]$} \\
\hline & & Octane & 1.664 & 1.654 & 0.59 & [20] \\
\hline & & Nonane & 1.797 & 1.797 & 0.00 & [20] \\
\hline \multirow[t]{5}{*}{ Ethyl acetate } & \multirow[t]{5}{*}{ n-Alkanes } & Pentane & 1.105 & 1.105 & 0.00 & [20] \\
\hline & & Hexane & 1.281 & 1.252 & 2.27 & [20] \\
\hline & & Heptane & 1.340 & 1.399 & 4.38 & [20] \\
\hline & & Octane & 1.575 & 1.546 & 1.83 & [20] \\
\hline & & Nonane & 1.692 & 1.692 & 0.00 & [20] \\
\hline \multirow[t]{5}{*}{ Acetic acid } & \multirow[t]{5}{*}{$n$-Alkanes } & Pentane & 2.455 & 2.509 & 2.17 & [20] \\
\hline & & Hexane & 2.789 & 2.789 & 0.00 & {$[20]$} \\
\hline & & Heptane & 3.114 & 3.076 & 1.24 & [20] \\
\hline & & Octane & 3.368 & 3.368 & 0.00 & [20] \\
\hline & & Nonane & 3.628 & 3.659 & 0.88 & [20] \\
\hline \multirow[t]{5}{*}{ Methanol } & \multirow[t]{5}{*}{$n$-Alkyl benzene } & Benzene & 1.946 & 1.946 & 0.00 & [21] \\
\hline & & Toluene & 2.313 & 2.157 & 6.72 & [21] \\
\hline & & Ethylbenzene & 2.632 & 2.663 & 1.17 & [21] \\
\hline & & Propylbenzene & 2.851 & 2.929 & 2.76 & [21] \\
\hline & & Butylbenzene & 3.211 & 3.211 & 0.00 & [21] \\
\hline \multirow[t]{5}{*}{ Acetonitrile } & \multirow[t]{5}{*}{$n$-Alkyl benzene } & Benzene & 1.065 & 1.065 & 0.00 & [21] \\
\hline & & Toluene & 1.459 & 1.255 & 13.97 & [21] \\
\hline & & Ethylbenzene & 1.723 & 1.740 & 0.99 & [21] \\
\hline & & Propylbenzene & 2.054 & 2.092 & 1.85 & [21] \\
\hline & & Butylbenzene & 2.407 & 2.407 & 0.00 & [21] \\
\hline \multirow[t]{5}{*}{ 2-Propanol } & $n$-Alkyl benzene & Benzene & 1.504 & 1.504 & 0.00 & [21] \\
\hline & & Toluene & 1.668 & 1.612 & 3.37 & [21] \\
\hline & & Ethylbenzene & 1.825 & 2.018 & 10.59 & [21] \\
\hline & & Propylbenzene & 1.946 & 2.052 & 5.47 & [21] \\
\hline & & Butylbenzene & 2.140 & 2.140 & 0.00 & [21] \\
\hline Acetone & $n$-Alkyl benzene & Benzene & 1.040 & 1.040 & 0.00 & [22] \\
\hline & & Toluene & 1.394 & 1.335 & 4.24 & {$[22]$} \\
\hline & & Ethylbenzene & 1.721 & 1.696 & 1.44 & [22] \\
\hline & & Propylbenzene & 2.053 & 2.068 & 0.76 & [22] \\
\hline & & Butylbenzene & 2.407 & 2.407 & 0.00 & [22] \\
\hline Methanol & 1-Alcohols & Ethanol & 1.497 & 1.497 & 0.00 & [22] \\
\hline & & 1-Propanol & 1.952 & 2.058 & 5.46 & [22] \\
\hline & & 1-Butanol & 2.166 & 2.569 & 18.61 & [22] \\
\hline & & 1-Pentanol & 3.513 & 3.113 & 11.38 & [22] \\
\hline & & 1-Hexanol & 3.790 & 3.656 & 3.53 & [22] \\
\hline & & 1-Heptanol & 4.197 & 4.197 & 0.00 & {$[22]$} \\
\hline
\end{tabular}


Tabl 4 (Continued)

\begin{tabular}{|c|c|c|c|c|c|c|}
\hline Solvent & Family of solute & Solute (B) & $\ln \gamma_{\mathrm{B}}^{\infty, \exp }$ & $\ln \gamma_{\mathrm{B}}^{\infty, \mathrm{cal}}$ & $\mathrm{AAD}^{\mathrm{a}}(\%)$ & Data ref. \\
\hline \multirow[t]{5}{*}{ Methanol } & 2-Ketones & Acetone & 1.224 & 1.224 & 0.00 & [22] \\
\hline & & 2-Butanone & 1.319 & 1.402 & 6.32 & [22] \\
\hline & & 2-Pentanone & 1.569 & 1.569 & 0.00 & [22] \\
\hline & & 2-Hexanone & 1.726 & 1.730 & 0.20 & [22] \\
\hline & & 2-Heptanone & 2.011 & 1.888 & 6.11 & [22] \\
\hline
\end{tabular}

a $\operatorname{AAD}(\%)=\frac{100}{\mathrm{NP}} \times \sum_{i}^{\mathrm{NP}}\left|\frac{\ln \gamma_{\mathrm{B}, i}^{\infty, \exp }-\ln \gamma_{\mathrm{B}, i}^{\infty, \mathrm{cal}}}{\ln \gamma_{\mathrm{B}, i}^{\infty, \exp }}\right|$.

Table 5

Comparison of the calculated $\ln \gamma^{\infty}$ values of non-aqueous mixtures at $298.15 \mathrm{~K}$ from various models

\begin{tabular}{|c|c|c|c|c|c|c|c|c|}
\hline \multirow[t]{2}{*}{ Solute } & \multirow[t]{2}{*}{ Solvent } & \multirow[t]{2}{*}{$\begin{array}{l}\text { Data points } \\
\text { (NP) }\end{array}$} & \multicolumn{2}{|c|}{$\begin{array}{l}\text { Parameters of the } \\
\text { m-AD model }\end{array}$} & \multicolumn{4}{|l|}{$\mathrm{AAD}^{\mathrm{a}}(\%)$} \\
\hline & & & $\alpha$ & $\beta$ & MOSCED & SPACE & m-UNIFAC & $\mathrm{m}-\mathrm{AD}$ \\
\hline \multirow[t]{6}{*}{$n$-Alkanes } & Ethanol & 5 & 0.053 & 0.166 & 2.35 & 5.45 & 2.62 & 1.03 \\
\hline & 1-Propanol & 5 & -0.648 & 0.627 & 2.57 & 2.52 & 4.20 & 0.86 \\
\hline & Acetone & 5 & -0.440 & 0.515 & 6.92 & 2.95 & 7.77 & 1.38 \\
\hline & 2-Butanone & 5 & -0.322 & 0.369 & 2.90 & 4.94 & 6.16 & 1.70 \\
\hline & Ethyl acetate & 5 & 0.332 & -0.099 & 5.92 & 25.6 & 4.23 & 1.70 \\
\hline & Acetic acid & 5 & 1.059 & -0.468 & N.A. & N.A. & 13.5 & 0.86 \\
\hline \multirow[t]{4}{*}{$n$-Alkyl benzene } & Methanol & 5 & -2.597 & 2.090 & 2.63 & 23.9 & 1.36 & 2.13 \\
\hline & Acetonitrile & 5 & 7.853 & -5.056 & 3.53 & 95.4 & 3.91 & 3.36 \\
\hline & 2-Propanol & 5 & -13.614 & 9.332 & 16.5 & 3.06 & 10.8 & 3.88 \\
\hline & Acetone & 5 & 6.060 & -3.846 & 60.9 & 91.6 & 59.1 & 1.29 \\
\hline 1-Alcohols & Methanol & 6 & -1.948 & 1.767 & 83.7 & 108 & 92.5 & 6.50 \\
\hline 2-Ketones & Methanol & 5 & 0.349 & 0.032 & 29.6 & 148 & 37.3 & 2.53 \\
\hline Grand & & 61 & & & 20.9 & 42.2 & 21.5 & 2.34 \\
\hline
\end{tabular}

a $\operatorname{AAD}(\%)=\frac{100}{\mathrm{NP}} \times \sum_{i}^{\mathrm{NP}}\left|\frac{\ln \gamma_{\mathrm{B}, i}^{\infty, \exp }-\ln \gamma_{\mathrm{B}, i}^{\infty, \mathrm{cal}}}{\ln \gamma_{\mathrm{B}, i}^{\infty, \exp }}\right|$.

parameters and were optimally fitted in this study using experimental $\gamma^{\infty}$ data of most systems listed in Table 4. The model parameters for the PDD and LSER equations are insufficient for non-aqueous systems and they are not included here for comparative study. The m-AD model also yields an acceptable AAD value of $2.34 \%$ for non-aqueous sys- tems. The MOSCED and SPACE models give satisfactory results within experimental accuracy for many systems. For methanol as solvent, the deviations of $\ln \gamma^{\infty}$ for 1-alcohols and 2-ketones from the MOSCED and SPACE models are quite large. Table 6 shows the experimental and calculated $\ln \gamma^{\infty}$ values for these systems, and the calculation

Table 6

Calculated results of $\ln \gamma^{\infty}$ for solutes in methanol solvent using various thermodynamic models

\begin{tabular}{|c|c|c|c|c|c|c|c|c|c|}
\hline \multirow[t]{2}{*}{ Solute (B) } & \multirow[t]{2}{*}{$\ln \gamma_{\mathrm{B}}^{\infty, \exp }$} & \multicolumn{4}{|l|}{$\ln \gamma_{\mathrm{B}}^{\infty, \mathrm{cal}}$} & \multicolumn{4}{|l|}{$\operatorname{AAD}^{\mathrm{a}}(\%)$} \\
\hline & & MOSCED & SPACE & m-UNIFAC & $\mathrm{m}-\mathrm{AD}$ & MOSCED & SPACE & m-UNIFAC & $\mathrm{m}-\mathrm{AD}$ \\
\hline Ethanol & 1.497 & 0.106 & -0.005 & -0.030 & 1.497 & 92.95 & 100.3 & 102.0 & 0.00 \\
\hline 1-Propanol & 1.952 & 0.246 & -0.080 & 0.045 & 2.058 & 87.41 & 104.1 & 97.67 & 5.46 \\
\hline 1-Butanol & 2.166 & 0.403 & -0.161 & 0.163 & 2.569 & 81.41 & 107.4 & 92.48 & 18.61 \\
\hline 1-Pentanol & 3.513 & 0.582 & -0.306 & 0.309 & 3.113 & 83.43 & 108.7 & 91.20 & 11.38 \\
\hline 1-Hexanol & 3.790 & 0.765 & -0.466 & 0.477 & 3.656 & 79.82 & 112.3 & 87.42 & 3.53 \\
\hline 1-Heptanol & 4.197 & 0.962 & -0.626 & 0.661 & 4.197 & 77.09 & 114.9 & 84.25 & 0.00 \\
\hline Acetone & 1.224 & 0.709 & -0.506 & 0.722 & 1.224 & 42.10 & 141.3 & 40.97 & 0.00 \\
\hline 2-Butanone & 1.319 & 0.868 & -0.683 & 0.824 & 1.402 & 34.21 & 151.8 & 37.53 & 6.32 \\
\hline 2-Pentanone & 1.569 & 1.105 & -0.812 & 0.962 & 1.569 & 29.56 & 151.8 & 38.65 & 0.00 \\
\hline 2-Hexanone & 1.726 & 1.349 & N.A. & 1.128 & 1.730 & 21.88 & N.A. & 34.66 & 0.20 \\
\hline 2-Heptanone & 2.011 & 1.603 & N.A. & 1.315 & 1.888 & 20.30 & N.A. & 34.61 & 6.11 \\
\hline
\end{tabular}

\footnotetext{
a $\operatorname{AAD}(\%)=\frac{100}{\mathrm{NP}} \times \sum_{i}^{\mathrm{NP}}\left|\frac{\ln \gamma_{\mathrm{B}, i}^{\infty, e \exp }-\ln \gamma_{\mathrm{B}, i}^{\infty, \mathrm{cal}}}{\ln \gamma_{\mathrm{B}, i}^{\infty, \operatorname{ex}}}\right|$.
} 


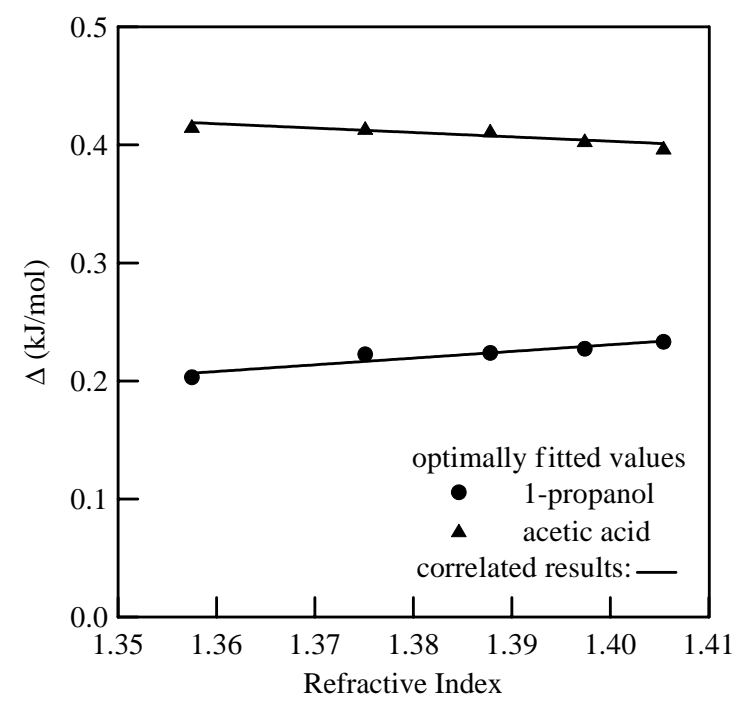

Fig. 3. Relationship between the interchange energy parameter and the refractive index of pure $n$-alkanes in organic solvents other than water.

deviations from various models. One reason for the large deviation from the MOSCED and SPACE models is that they did not include methanol as solvent in their generalized regression. Various experimental techniques may yield different $\gamma^{\infty}$ values and further evaluations are appreciable. For methanol as a solvent in non-aqueous systems, $\gamma^{\infty}$ values are approximately within $\pm 5 \%$ for methanol $+n$-alkyl benzenes using static, ebulliometry, or gas-liquid chromatography experimental methods [22]. In our correlation, we prefer data from one literature source that provided most of the components in a homologous series. For methanol $+n$-alkyl benzene homologous series, our correlation is still the same if we include all available experimental data from various measurement methods, as shown in Fig. 4.

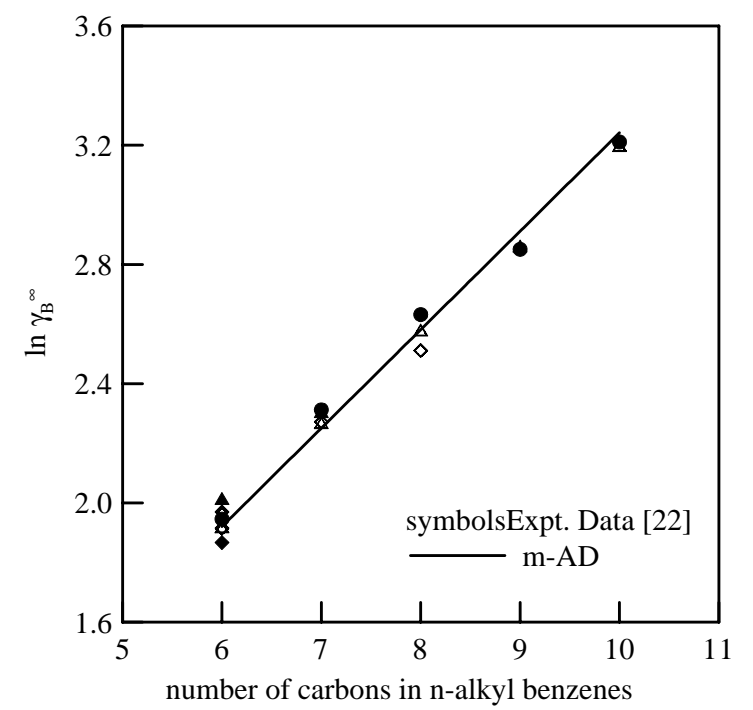

Fig. 4. Correlation of infinite dilution activity coefficients for $n$-alkyl benzenes in methanol using all available experimental data [22].

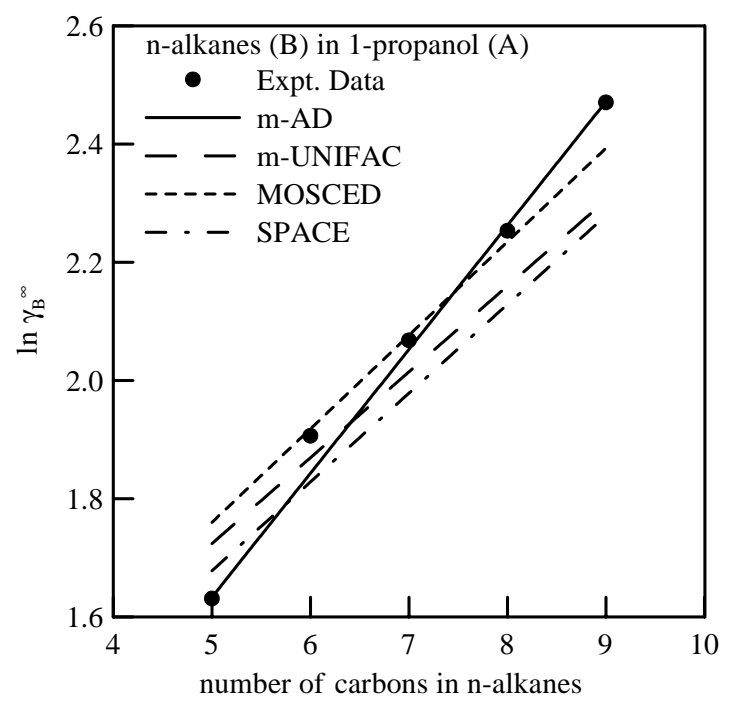

Fig. 5. Comparison of the calculated infinite dilution activity coefficients from various methods for $n$-alkanes (B) in 1-propanol (A) at $298.15 \mathrm{~K}$.

The grand AAD for this series shown in Table 5 is about $7 \%$ in $\gamma^{\infty}$ that is reasonable with respect to experimental accuracy. For homologous series of methanol +1 -alcohol or methanol +2 -ketones, experimental data show scattering effect even from the same literature source [22]. The correlation error from this $\mathrm{m}-\mathrm{AD}$ model is relatively larger for methanol +1 -alcohols as shown in Table 6. Fig. 5 shows the graphical comparisons of the calculated $\ln \gamma^{\infty}$ of $n$-alkanes in 1-propanol where the m-AD model gives good results. The MOSCED model presents good predictions, but shows larger errors for $\mathrm{n}$-alkanes with shorter or longer chains. Based on these observations, the m-AD model is considered to be a reliable correlation model with generalized parameters for homologous series in non-aqueous organic systems.

The m-AD model is further tested for predicting the $\ln \gamma^{\infty}$ values of solutes not included in the correlation. One example is shown in Fig. 6 for aqueous mixtures of heavy 1 -alcohols. It is observed that both the PDD and m-AD models show reasonable results with an AAD value around $2 \%$ for $\ln \gamma^{\infty}$. The LSER or the m-UNIFAC model, however, presents relatively larger error. Fig. 7 demonstrates the relative error distribution for four methods for aqueous mixtures of 1-alcohols $\left(\mathrm{C}_{8}-\mathrm{C}_{10}\right.$, and $\left.\mathrm{C}_{12}\right)$, aldehydes $\left(\mathrm{C}_{7}-\mathrm{C}_{9}\right)$ and 2-alcohols $\left(\mathrm{C}_{3}-\mathrm{C}_{6}\right)$. This figure illustrates again that the $\mathrm{m}-\mathrm{AD}$ and PDD models give comparable and reliable predictions. For PDD model, parameters for many non-aqueous systems are lacking. The m-AD model is satisfactorily examined for generalized correlation of $\ln \gamma^{\infty}$ on both aqueous and organic solvents. For calculations of $\gamma^{\infty}$ at temperatures other than $298.15 \mathrm{~K}$, partial molar enthalpy data are required. The application of the m-AD model on vapor-liquid and liquid-liquid equilibrium calculations is also feasible [23], and numerical evaluations are ongoing. 


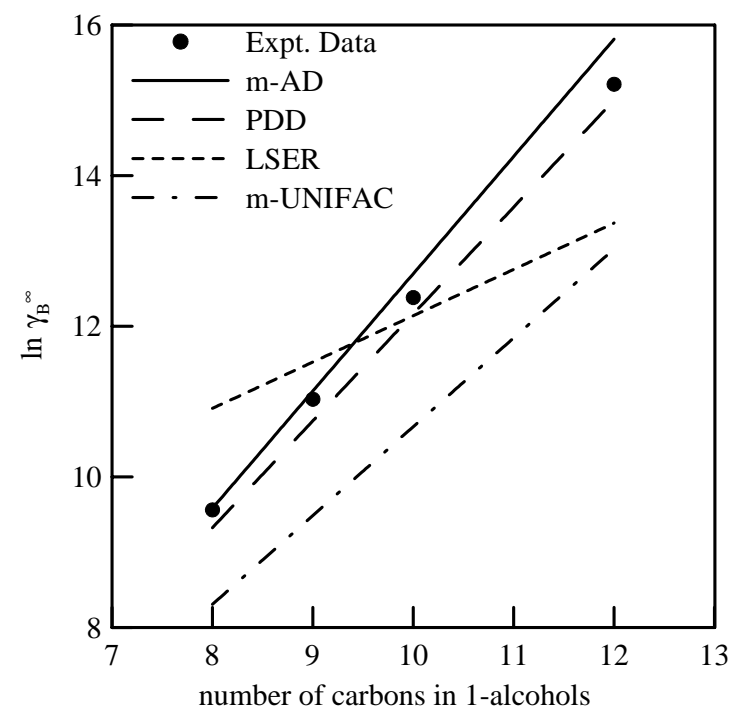

Fig. 6. Comparison of the predicted infinite dilution activity coefficients from various methods for 1-alcohols (B) aqueous mixtures at $298.15 \mathrm{~K}$.

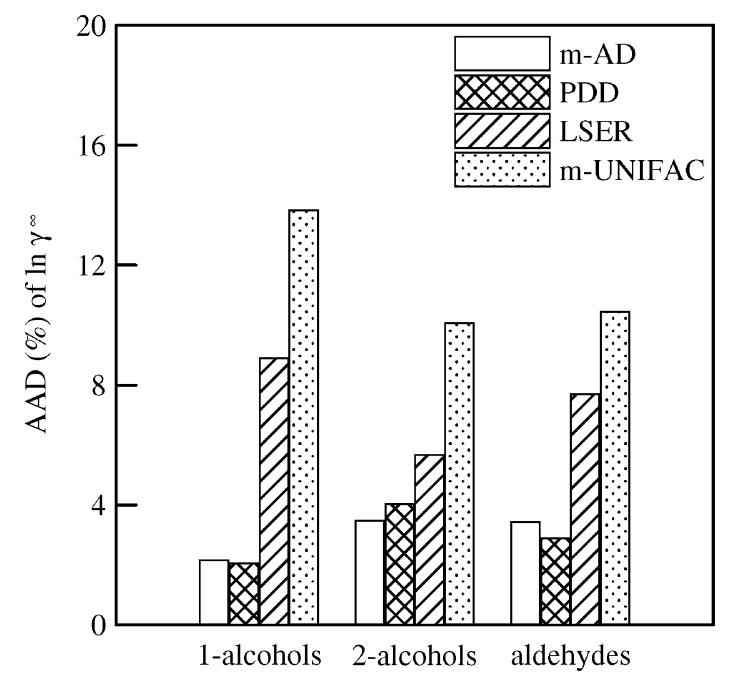

Fig. 7. Comparison of the predicted AAD of infinite dilution activity coefficients from various methods for aqueous mixtures at $298.15 \mathrm{~K}$.

\section{Conclusion}

An m-AD excess Gibbs energy model based on the concept of a local-composition lattice fluid is proposed in this study. Infinite dilution activity coefficients in aqueous and organic solutions are evaluated and compared using the $\mathrm{m}-\mathrm{AD}$, and other predictive models of PPD, MOSCED, SPACE, LSER and the m-UNIFAC. These predictive models are with less parameter than the correlative method, however, in some systems they give larger deviations. With two generalized parameters for each homologous series of solutes, the m-AD model yields satisfactory results with overall smaller deviations compared to various methods. Generalization of the
m-AD model parameters also makes predictive calculations feasible.

\section{List of symbols}

A, B component of solvent or solute

$d \quad$ dimension of a lattice site

$g \quad$ molar Gibbs energy

$H, h \quad$ total and molar enthalpy, respectively

$k_{\mathrm{B}} \quad$ Boltzmann constant

$N \quad$ number of molecules

$q \quad$ molecular surface area parameter

$r \quad$ molecular volume parameter

$R \quad$ gas constant

$S \quad$ entropy

$T \quad$ temperature

$U, u \quad$ total and molar internal energy, respectively

$x \quad$ mole fraction

$X, Y \quad$ probability or local composition

$z \quad$ coordination number, $z$ equals 6 in the $\mathrm{m}-\mathrm{AD}$ model

Greek letters

$\alpha, \beta \quad$ correlation constants

$\gamma \quad$ activity coefficient

$\Delta \quad$ interchange energy

$\varepsilon \quad$ intermolecular energy

$\theta \quad$ surface fraction parameter

$\phi, \phi^{\prime} \quad$ volume fraction parameter

\section{Superscripts}

cal calculated values

C combinatorial contribution

exp experimental data

E excess property

$\mathrm{R}$ residual contribution

$\infty \quad$ infinite distance or infinite dilution state

\section{Acknowledgements}

The authors are grateful to the support from the National Science Council, ROC and the Yen Tjing Ling Industrial Research Institute of National Taiwan University.

\section{References}

[1] J.S. Cheng, M. Tang, Y.P. Chen, Fluid Phase Equilib. 194-197 (2002) 483-491.

[2] C.C. Chen, AIChE J. 42 (1996) 3231-3240.

[3] T. Lindvig, L.L. Hestkjær, A.F. Hansen, M.L. Michelsen, G.M. Kontogeorgis, Fluid Phase Equilib. 194-197 (2002) 663-673.

[4] P. Kolář, J.W. Shen, A. Tsuboi, T. Ishikawa, Fluid Phase Equilib. 194-197 (2002) 771-782.

[5] G.J. Pierotti, C.H. Deal, E.L. Derr, Ind. Eng. Chem. 51 (1959) 95102.

[6] E.R. Thomas, C.H. Eckert, Ind. Eng. Chem. Process Des. Dev. 23 (1984) 194-209. 
[7] M.J. Hait, C.L. Liotta, C.A. Eckert, D.L. Bergmann, A.M. Karachewski, A.J. Dallas, D.I. Eikens, J.J. Li, P.W. Carr, R.B. Poe, S.C. Rutan, Ind. Eng. Chem. Res. 32 (1993) 2905-2914.

[8] S.R. Sherman, D.B. Trampe, D.M. Bush, M. Schiller, C.A. Eckert, A.J. Dallas, J. Li, P.W. Carr, Ind. Eng. Chem. Res. 35 (1996) 1044 1058.

[9] E.C. Voutsas, D.P. Tassios, Ind. Eng. Chem. Res. 35 (1996) 14381445 .

[10] S. Zhang, T. Hiaki, M. Hongo, K. Kojima, Fluid Phase Equilib. 144 (1998) 97-112.

[11] C.B. Castells, P.W. Carr, D.I. Eikens, D. Bush, C.A. Eckert, Ind. Eng. Chem. Res. 38 (1999) 4104-4109.

[12] S. Zhang, T. Hiaki, K. Kojima, Fluid Phase Equilib. 149 (1998) $27-40$.

[13] S. Zhang, T. Hiaki, K. Kojima, Fluid Phase Equilib. 198 (2002) $15-27$.

[14] G.L. Aranovich, M.D. Donohue, J. Chem. Phys. 105 (1996) 70597063.
[15] D.W. Wu, Y. Cui, M.D. Donohue, Ind. Eng. Chem. Res. 37 (1998) 2936-2946.

[16] J. Gmehling, J. Li, M. Schiller, Ind. Eng. Chem. Res. 32 (1993) 178-193.

[17] K. Kojima, S. Zhang, T. Hiaki, Fluid Phase Equilib. 131 (1997) $145-179$.

[18] D. Mackay, W.Y. Shiu, J. Phys. Chem. Ref. Data 10 (1981) 1175 1199.

[19] J. Li, A.J. Dallas, D.I. Eikens, P.W. Carr, D.L. Bergmann, M.J. Hait, C.A. Eckert, Anal. Chem. 65 (1993) 3212-3218.

[20] C.B. Castells, D.I. Eikens, P.W. Carr, J. Chem. Eng. Data 45 (2000) 369-375.

[21] W.J. Cheong, P.W. Carr, J. Chromatogr. 500 (1990) 215-239.

[22] J. Gmehling, J. Menke, M. Schiller, Activity Coefficient at Infinite Dilution, Dechema Data Series, vol. IX, Part 3, DECHEMA, Frankfurt/Main, 1994.

[23] J.S. Cheng, Ph.D. dissertation, National Taiwan University, 2003. 